\title{
Condom Use Consistency and Associated Factors Among College Student Men Who Have Sex with Men from Seven Colleges in Changsha City: A Cross-Sectional Survey
}

\author{
Honghong Wang $\mathbb{D}^{1, *}$ \\ Simin $\mathrm{Yu}\left(\mathbb{D}^{1}{ }^{1, *}\right.$ \\ Wendy Cross $\mathbb{D}^{2}$ \\ Louisa Lam (1D) ${ }^{2}$ \\ Biswajit Banik (iD) ${ }^{2}$ \\ Kaili Zhang $\mathbb{D}^{3}$
}

'Xiangya School of Nursing, Central South University, Changsha City, 410000, Hunan Province, People's Republic of China; ${ }^{2}$ School of Health, Federation University, Berwick, 3806, Victoria, Australia; ${ }^{3}$ School of Nursing, Xuzhou Medical University, Xuzhou City, 221004, jiangsu Province, People's Republic of China

*These authors contributed equally to this work
Correspondence: Kaili Zhang Nursing School of Xuzhou Medical University, 209 Tongshan Road, Xuzhou, 221004, Jiangsu, People's Republic of China

Tel/Fax +86-516-83262165

Email xiaokai20060@xzhmu.edu.cn
Background: College student men who have sex with men (MSM) are at high risk for HIV infection due to multiple social and behavioral factors. Consistent condom use is nationally advocated for HIV prevention. This study explored the sexual behaviors and factors associated with condom use consistency in the past six months among college student MSM from seven colleges in Hunan Province, China.

Methods: A cross-sectional survey was conducted from September 2017 to March 2018. Condom use consistency, sexual behaviors, HIV testing performance, substance use, and alcohol consumption were examined using researcher-created questionnaires. Condom use self-efficacy and HIV-related knowledge were assessed using the Condom Use Self-Efficacy Scale and the unified National AIDS Sentinel Surveillance Questionnaire. Univariate and multivariate logistic regressions were used. $\mathrm{P}<0.05$ was considered significant.

Results: In the 214 respondents, the rate of consistent condom use was $56 \%(n=119)$ during the past six months. Participants who were studying at first-tier universities (odds ratio [OR]: 2.522, 95\% confidence interval [CI]: 1.255-5.067) and had higher scores for condom use self-efficacy (OR: 2.617, 95\% CI: 1.462-4.685) were more likely to report consistent condom use than the others. The risk factor was having suspicious symptoms of sexually transmitted diseases (OR: 0.357, 95\% CI: 0.163-0.780).

Conclusion: Numerous students were at high risk of HIV infection with inconsistent condom use. Comprehensive and specific topics about safe sex education from parents and peers should be offered on campuses in China.

Keywords: college student men who have sex with men, condom use consistency, sexual behaviors, sex education

\section{Introduction}

According to statistics from the Joint United Nations Program on HIV/AIDS, 38.0 million people were living with HIV, and 1.7 million people were newly infected with HIV globally in 2019. ${ }^{1}$ In China, 131,000 new cases of AIDS were reported, and over 958,000 people were living with HIV by the end of October 2019. ${ }^{2}$ According to global data, the alarming prevalence of HIV acquisition was 26 times higher among men who have sex with men (MSM) than among all adults in 2019. ${ }^{1}$ In 2018, MSM accounted for an estimated $17 \%$ of new HIV infections globally. ${ }^{3}$ Student MSM, an alarming subgroup of MSM, increased HIV 
prevalence in China. In recent years, approximately 3000 HIV cases every year have comprised young students aged 15-24 years, and male students have accounted for $80 \%$ of the infections. ${ }^{4}$ Male-to-male sexual transmission is the most common transmission route. ${ }^{5}$ The rate of male-tomale sexual transmission among young students increased from $58.5 \%$ in 2008 to $81.6 \%$ in $2014 .{ }^{6}$ Similarly, the Chinese Center for Disease Control and Prevention (CDC) reported that new HIV infections among college students increased by $35 \%$ annually from 2011 to 2015 , with student MSM accounting for $82 \%{ }^{7}$ Data from 2015 to 2017 in Nanjing, China, showed that among 156 HIVpositive college students, 154 (98.7\%) were men, and 148 male students $(96.1 \%)$ were infected through sexual intercourse with men. ${ }^{8}$ The rapid increase in HIV prevalence highlights college student MSM as a high-risk and extremely vulnerable population.

Compared with female students in college, male students, particularly MSM, are more open about sexual attitudes. ${ }^{9}$ They are more likely to engage in high-risk sexual behaviors, including inconsistent condom use with casual sex partners, having commercial sex, and/or having multiple sex partners. ${ }^{10,11}$ Several common HIV-related risk factors have been reported among young MSM. These factors include inconsistent condom use, ${ }^{12,14}$ having multiple sex partners, ${ }^{12}$ one-night stand behavior, ${ }^{13}$ having sex with HIV-positive partners, ${ }^{12,14}$ using drugs or alcohol before or during sex, ${ }^{15}$ and gay app use. ${ }^{16}$ Similarly, college male students tend to have vague HIV prevention knowledge, ${ }^{9}$ are less likely to use HIV prevention services, and/or barely participate in HIV and sexually transmitted disease (STD) testing. ${ }^{14,17}$ Therefore, for college student MSM, the inconsistency of condom use is a main risk factor in the transmission of HIV. ${ }^{18-20}$ A meta-analysis in 2015 revealed that $65.2 \%$ of Chinese student MSM had unprotected anal intercourse (UAI) in the past six months. However, the rate of student MSM who reported using condoms in their last homosexual anal intercourse was only $57.5 \%{ }^{18}$ Similarly, a study conducted in three northern regions of China in 2018 reported that $41.1 \%$ of college student MSM used condoms inconsistently in the past six months. ${ }^{19}$ Therefore, an investigation on consistent condom use and an exploration of the associated factors related to high-risk sexual behavior can help in decision making to reduce new HIV infections among college student MSM.

Before this study was conducted, some measures for HIV prevention were implemented for the benefit of college students. However, the effect was not significant. To regulate health education on HIV/AIDS prevention in schools, the Chinese government has issued several policies, including the "Notice on Strengthening Health Education on AIDS Prevention in Schools," which was jointly issued by the Ministry of Education and the Ministry of Health in 2002, ${ }^{20}$ and the "Basic Knowledge on HIV/AIDS Prevention for Youth," which was jointly issued by the Ministry of Health and the Ministry of Education in May 2007. ${ }^{21}$ In 2015, the Ministry of Education and the Ministry of Health jointly issued a document on HIV prevention, which included establishing a school AIDS epidemic notification system, improving the coverage and relevance of AIDS prevention education in schools, and strengthening Voluntary Counseling and Testing (VCT) services and interventions for behaviors. ${ }^{22}$ In 2019, the Ministry of Education and the National Health and Family Planning Commission jointly issued the "Notice on Further Strengthening HIV/ AIDS Prevention Education in Schools in the New Era," which emphasized that each school should carry out health education suitable for the physical and mental characteristics of adolescents and strengthen health education according to different educational stages. ${ }^{23}$ However, a large percentage of schools does not put the policy into practice: nearly half of the schools have not effectively implemented the policy requirements, such as not incorporating HIV/AIDS prevention health education into school teaching plans, not distributing HIV/AIDS prevention health education-related promotional materials to new students during their medical checkups, and not equipping libraries or reading rooms with HIV/AIDS prevention science books for students to read. ${ }^{24}$ A previous study conducted in Hunan Province in 2017 among 1431 male undergraduate students, among whom $49(3.42 \%)$ were MSM students, showed that 1068 (74.6\%; 95\% confidence interval [CI]: 72.4-76.0) used HIV prevention education services provided by colleges/universities, including publicity materials/billboards and lectures, but only 105 (7.3\%) male students underwent HIV testing. ${ }^{9}$ What was worse, young students often had misconceptions about HIV/AIDS, such as HIV/AIDS being distant from campus and having nothing to do with them. They wrongly believed that "he is my classmate, so he is safe" and that "we have known each other for a long time, and I believe he is HIV negative." 5 Young students in college are becoming more and more independent in study and life, and they make their own decisions in time management, 
recreational activities, and making friends. The limitations imposed by their parents and schools gradually fade away as they leave home and are away from their parents compared with the previous stages of their lives. Moreover, young students are always curious about the world, and many of them pursue physical and psychological stimulations, which makes them neglect the prevention and control of HIV infection. ${ }^{5,24}$ Therefore, there are precise measurements needed to be taken to provide proper sex education to college student MSM to help them learn to protect themselves.

Lowering new HIV infections among college student MSM is a public health priority, and consistent condom use is a core component of prevention efforts in China and around the world. Research interest in student MSM, a group with a high risk of HIV infection, has been recently renewed. However, little research has examined condom use consistency and risky sexual behaviors, specifically among college student MSM. Thus, this study aimed to explore condom use consistency and associated factors among college student MSM in China and to provide evidence for the further design of HIV prevention programs.

\section{Materials and Methods Study Design and Participants}

The survey was conducted in a local gay-friendly community-based organization (CBO) and in an HIV consulting room at a university in Changsha City. The $\mathrm{CBO}$ is located at the third level of a community health center in a wellconcealed position and is supervised by the CDC of Hunan Province. It was founded in 2008 and has excellent experience in consulting and testing for HIV. In the past 11 years, the $\mathrm{CBO}$ has undertaken approximately $70 \%$ of the testing tasks for MSM in Hunan Province. In 2017, an HIV consulting room was established at Central South University, which is supervised by the Yuelu District CDC of Changsha City and the Campus Hospital of a university.

Changsha is the capital city of Hunan Province, Southeast China, with an area of $211,829 \mathrm{~km}^{2}$ and a population of approximately 8.39 million. Changsha City is also the center of higher education in Hunan Province, with numerous college students from all districts of China and, therefore, a sizable number of student MSM. Changsha City is famous for its wealthy media and entertainment industries, with dozens of gay clubs, dance halls, and karaoke halls.
Snowball sampling instead of probability sampling was used to recruit college MSM for two reasons. First, college MSM tend not to report their MSM identity in the general survey because of social discrimination towards MSM. In our previous study of 1431 male college students, 49 reported that they were MSM and sexually active. ${ }^{9}$ Second, MSM are a hard-to-reach population who often hide and are reluctant to reveal that they are MSM or details about their sex life. Participant recruitment was conducted using two approaches. First, potential participants were sent posts through Blued, which is a social app for making gay friends, and WeChat, which is a Chinese social app for communication, social media, and other purposes, to invite them to the $\mathrm{CBO}$ or the HIV consulting room on campus. Second, people who usually went to the $\mathrm{CBO}$ or the HIV consulting room on campus for testing and met the inclusion criteria were invited to participate. Two well-trained researchers briefed these students about the purpose of the study, methodology, confidentiality, and compensation (a package of condoms and lubricants valued at approximately $50 \mathrm{RMB}$ ) for the time and transportation expenses of the participants. After their consent was obtained, the participants scanned a QR code given by the researchers, which led them to an online survey homepage supported by Wenjuanxing Company, a company that helps with online survey collection. The participants completed the survey within approximately 20-30 min. All participants were provided with free HIV consultations and rapid HIV testing after the completion of the survey. The study was conducted between September 2017 and March 2018.

The target population of this study was male college students, 16 years old and above, who had had at least one male partner in the past six months. The seven colleges in Hunan Province have diverse students from different areas. The sample size was calculated using the formula $\mathrm{n}=\frac{\mu_{\alpha / 2^{2}}^{2}(1-\pi)}{\delta^{2}}$. The following calculation was used to determine the sample size: $\alpha=0.05$, where $\delta$ is the allowable error assumed to be $3 \%$, and $\pi$ is the consistent condom use rate of $0.21 .^{25}$ The final sample size was 222 after allowing for $10 \%$ invalid questionnaires.

\section{Variables and Measurements}

Condom use consistency, sexual behaviors, HIV testing performance, substance use, and alcohol consumption were examined using researcher-created questionnaires. Condom use self-efficacy and HIV-related knowledge 
were assessed using the Condom Use Self-Efficacy Scale and the unified National AIDS Sentinel Surveillance Questionnaire. After suggestions from experts (Professor Xianhong $\mathrm{Li}$ and Professor Lloyd A. Goldsamt), CBO staff, and several college student MSM, the overall questionnaire was finalized. The final version of the questionnaire included 62 questions in seven areas: (a) demographic characteristics, (b) HIV knowledge, (c) sexual behaviors, (d) HIV testing performance, (e) substance use and alcohol consumption, (f) condom use self-efficacy, and $(\mathrm{g})$ condom use consistency in the past six months.

\section{Demographic Characteristics}

Demographic characteristics included age, ethnicity, school type, grade, study area, monthly living expenses, and sexual orientation.

\section{HIV Knowledge}

HIV-related knowledge was assessed using the eight-item national AIDS sentinel surveillance questionnaire. The questionnaire was developed based on the unified national AIDS sentinel surveillance questionnaire designed specifically for university students. ${ }^{26}$ Through a yes/no/uncertain format for each item, only the correct response was scored one point. Participants having a total score of six or higher were recognized as having "sufficient knowledge;" otherwise, they were regarded as having "insufficient knowledge." The internal reliability (KR-20) of this questionnaire was 0.64 .

\section{Sexual Behaviors}

The sexual behaviors of the participants were assessed by inquiring about their age during their first insert sex experience, which included anal sex, oral sex, and virgin sex; age during the first time they had sex with a man; the role they usually play when having homosexual sex; the number of male sex partners in the past six months; whether they exchanged sex for money or preferred the services of sex-to-pay boys in the past six months; frequency of casual sexual encounters in the past six months; whether they had regular partners in the past six months; places where they usually find male sex partners; and whether they preferred someone who was a student or an older MSM who had left school or was employed.

\section{HIV Testing Performance}

The participants were asked about their number and frequency of HIV testing and the date of their last test. The participants with no prior HIV testing were asked about their reasons for not undergoing testing and whether they had ever suspicious STD symptoms.

\section{Substance Use and Alcohol Consumption}

The participants were asked whether they had consumed alcohol or used substances, such as alkyl nitrites ("poppers"), ketamine, cocaine, opium, morphine, crack cocaine, and marijuana, in the past six months. They were also asked how many times they used substances or alcohol before or during sex.

\section{Condom Use Self-Efficacy}

Condom use self-efficacy is defined as a person's confidence in their ability to use condoms. ${ }^{27}$ The Condom Use Self-Efficacy Scale, which was developed for the Chinese MSM population and previously used for MSM in Sichuan Province, was used in this study. ${ }^{28}$ The eight-item scale (Cronbach's $\alpha=0.838$, Spearman-Brown $=0.778$ ) was used to assess the judgment or belief about whether they could decide to use condoms in a virtual situation of their upcoming sexual activities and their ability to communicate and negotiate condom use with sex partners in various situations. The participants defined each item in a confident/unconfident/uncertain format. For each item, "confident," "uncertain," and "unconfident" were given scores of two, one, and zero, respectively. A composite score was obtained by summing the scores of each item. A score higher than the median indicated confidence in condom use.

\section{Condom Use Consistency}

The participants were evaluated for their condom use consistency by inquiring about their overall condom use frequency during the past six months, specifically their condom use frequency with regular partners, commercial sex partners, and casual sex partners. Furthermore, they were asked whether they used condoms during their last anal sex; if their answer was "no," the reasons for not doing so were asked.

\section{Ethical Considerations}

Ethical approval was obtained from the Institutional Review Board of Xiangya Nursing School, Central South University (Changsha, China). Essential information about the study, including the purpose and procedures of the study, the benefits and risks of the participants, and their right to decline participation in the study, was explained by the investigators. Therefore, the completion of the 
questionnaire was considered to provide consent for participation in the study. All data were encrypted and kept by a dedicated person to ensure data confidentiality.

\section{Statistical Analysis}

Descriptive analysis was conducted for all variables. Logistic regression analysis was performed to identify the factors associated with condom use consistency in the past six months. Independent variables found to have statistical significance in the univariate regression analysis were screened and entered into the final multivariate regression model. Data management and analysis were performed using SPSS 25.0 software. ${ }^{29}$ Statistical tests were two-sided, and a p-value of $<0.05$ was considered to indicate statistical significance.

\section{Results}

\section{Sociodemographic Characteristics of the Participants}

In total, 222 questionnaires were collected through the survey, eight of which did not contain responses to the key variables. Therefore, 214 valid questionnaires were included in the analysis. The participants' ages ranged from 16 to 26 years $($ mean $=20.46$ years; $\mathrm{SD}=0.108$ ). Most of them were of Han ethnicity $(n=196,91.6 \%)$, came from urban districts $(\mathrm{n}=109,50.9 \%)$, and had living expenses of 1001-2000 RMB (approximately $142-283$ USD) per month $(\mathrm{n}=156,72.9 \%)$. The majority of the respondents were sophomore students $(n=59$, $27.6 \%)$ who came from first-tier colleges $(\mathrm{n}=121$, $56.5 \%)$ and majored in non-medical fields $(\mathrm{n}=189$, $88.3 \%$ ). The majority of the students regarded themselves as homosexual $(\mathrm{n}=170,79.4 \%)$, whereas the remaining considered themselves as either bisexual $(\mathrm{n}=40,18.7 \%)$ or unclear $(\mathrm{n}=4,1.90 \%)$ (Table 1$)$.

\section{HIV Knowledge}

In summary, 204 (95.3\%; 95\% CI: 92.0-98.0) students scored six points or above in HIV-related knowledge and were considered to have sufficient knowledge. Among the eight HIV knowledge questions, two were mostly answered correctly; $99.1 \%$ of the students believed that using condoms would reduce the risk of HIV transmission, and $99.7 \%$ thought that sharing needles with an HIVpositive person would cause HIV infection. Two items had a correct response rate of below $85 \%$. The items that assessed knowledge on whether one could be infected through mosquito bites and whether having sex with only one faithful, uninfected partner could reduce the risk of HIV transmission, and they had correct response rates of $84.1 \%$ and $83.6 \%$, respectively.

\section{HIV Testing Performance}

Almost two-thirds of the participants $(\mathrm{n}=135,63.1 \%)$ had at least one HIV test, and approximately nine in every 10 students $(n=121,89.6 \%)$ reported HIV testing in the past 12 months. The top three reasons why 79 students (10.4\%) never had HIV testing were a firm belief in non-HIV infection $(\mathrm{n}=41,51.9 \%)$, fear of disclosure of their privacy $(\mathrm{n}=28,35.4 \%)$, and fear of being diagnosed positive with HIV $(\mathrm{n}=24,30.4 \%)$.

\section{Substance Use and Alcohol Consumption}

In summary, 30 participants (14\%) reported substance use in the past six months. Rush popper $(\mathrm{n}=29,96.7 \%)$ and marijuana $(\mathrm{n}=1,3.3 \%)$ were mostly used. Twenty-one participants reported at least one time male-to-male sex after using substances. Nearly half of the students (104, $48.6 \%$ ) reported alcohol consumption, and nine students had male-to-male sex at least once after drinking alcohol.

\section{Condom Use Self-Efficacy}

The average score of the eight items of the Condom Use Self-Efficacy Scale was 13.65 ( $\mathrm{SD}=3.37,95 \%$ CI: 13.$20-14.10$, median $\left.=15.0, \mathrm{P}_{25}=12.52, \mathrm{P}_{75}=15.92\right)$. Among the eight confident/unconfident/uncertain format items, the two items "I am able to discuss condom use with any of my sex partners" and "I can advise to use condoms even when I'm not sure whether my sex partner likes using it or not" were answered with "confident" by $88.3 \%(n=189)$ and $90.2 \%(n=193)$ of the students, respectively. However, the two other items, "I can insist on using condoms even when I advise to use condoms and my sex partner gets angry" and "I can insist on using condoms when my sex partner is drunk," were mostly answered with "not sure" and "not confident" at $24.3 \%(\mathrm{n}=52)$ and $36.7 \%(n=79)$, respectively.

\section{Sexual Behaviors}

The students' age at first sex was 11-23 years. Most $(n=202$, $94.4 \%$ ) of them had their first sex with a male. Regarding the sex role they usually played, 49 participants $(22.9 \%)$ preferred to be " 0 " (docile, bottom) only, 32 (15.0\%) preferred to be " 1 " (assertive, top) only, and the rest of the participants reported playing both "0" and "1." Among the participants, 
Table I Demographic Characteristics of College Student MSM $(N=214)$

\begin{tabular}{|c|c|c|c|}
\hline Item & Category & Number & Percent (\%) \\
\hline \multirow[t]{4}{*}{ Age (years) } & $16-18$ & 15 & 7.0 \\
\hline & $|9-2|$ & 148 & 69.2 \\
\hline & $22-24$ & 49 & 22.9 \\
\hline & $>24$ & 2 & 0.9 \\
\hline \multirow[t]{2}{*}{ Ethnicity } & Han & 196 & 91.6 \\
\hline & Others & 18 & 8.4 \\
\hline \multirow[t]{2}{*}{ Area of residence } & Urban area & 109 & 50.9 \\
\hline & Rural area & 105 & 49.1 \\
\hline \multirow[t]{4}{*}{ School type } & Vocational college & 52 & 24.3 \\
\hline & Third-tier universities & 8 & 3.7 \\
\hline & Second-tier universities & 33 & 15.4 \\
\hline & First-tier universities & 121 & 56.5 \\
\hline \multirow[t]{4}{*}{ Grade } & Freshman & 49 & 22.9 \\
\hline & Sophomore & 59 & 27.6 \\
\hline & Junior & 53 & 24.8 \\
\hline & Senior and above & 53 & 24.8 \\
\hline \multirow[t]{2}{*}{ Profession } & Medical-related fields & 25 & 11.7 \\
\hline & Non-medical fields & 189 & 88.3 \\
\hline \multirow[t]{4}{*}{ Living expenses per month (RMB) } & $\leq 1000$ & 28 & 13.1 \\
\hline & $100 \mid-2000$ & 156 & 72.9 \\
\hline & $200 I-3000$ & 20 & 9.3 \\
\hline & $>3000$ & 10 & 4.7 \\
\hline \multirow[t]{3}{*}{ Sexual orientation } & Homosexual & 170 & 79.4 \\
\hline & Bisexual & 40 & 18.7 \\
\hline & Unclear & 4 & 1.90 \\
\hline
\end{tabular}

112 students $(52.3 \%)$ had only one sex partner in the past six months, 90 (41.9\%) had two to five male partners, and 12 $(5.8 \%)$ had more than six male sex partners. The most popular approach to finding a male sex partner was via mobile dating apps $(n=204,95.3 \%)$ (Figure 1). Four, five, and three students reported having one-, two-, and three-time group sex in the past six months, respectively. When they were asked whether they preferred their sex partners to be a student or someone who was employed or left school, half of them $(n=108,50.5 \%)$ preferred students, and $90(42.1 \%)$ reported having no preference and being solely reliant on their feelings (Table 2).

\section{Condom Use Consistency}

Regarding the overall frequency of condom use in the past six months, $26(12.2 \%)$ students claimed that they never or rarely used condoms, 18 (8.4\%) sometimes used condoms, 51 (23.8\%) often used condoms, and 119 (55.6\%) used condoms every time. The participants who used condoms every time were considered to be using condoms 


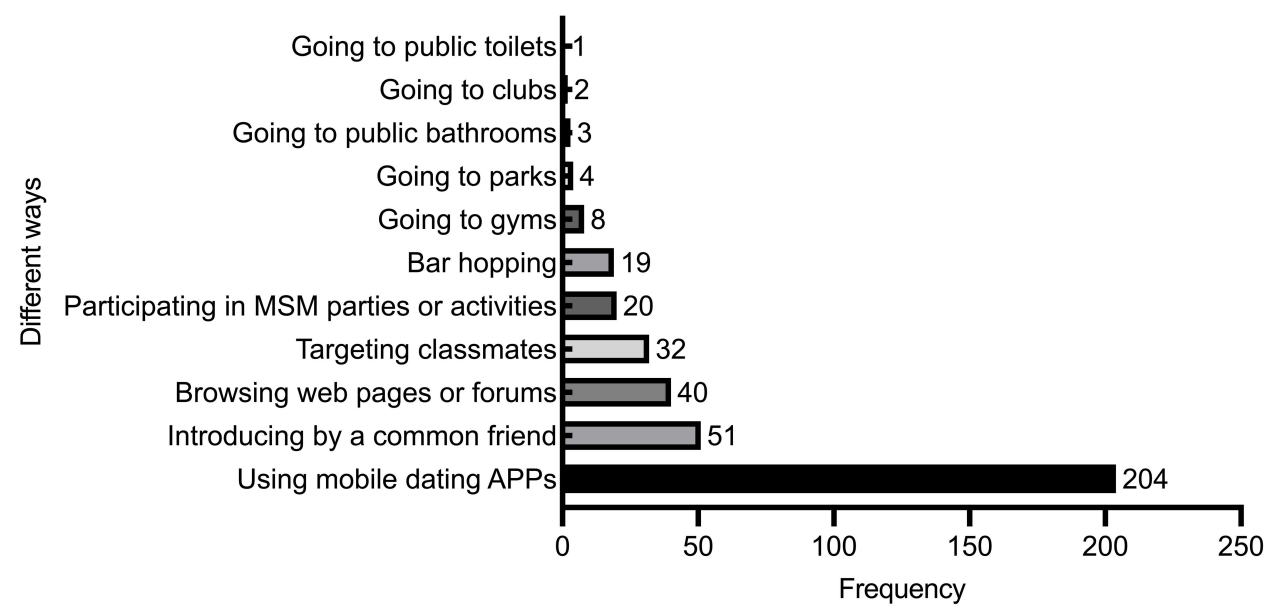

Figure I Preferable ways to find male sexual partners ( $N=2 \mid 4$, multiple choices).

consistently. Fifty-one (23.8\%) students reported that they had not used condoms the last time they had sex with a male sex partner.

Only one student had had a commercial sex partner in the past six months, and he did not use condoms every time. Furthermore, 95 (44.4\%) students had one-night stand/casual sexual encounters, 58 (61.1\%) of whom used condoms every time, and $12(12.6 \%)$ never used condoms. Among the participants, 121 (56.5\%) had regular sex partners. Regarding the frequency of condom use with regular partners in the past six months, 70 (32.7\%) students used condoms every time, 39 (18.2\%) used condoms inconsistently, and 12 (5.6\%) never used condoms with regular sex partners. Five students reported having female partners and using condoms every time to avoid pregnancy in the past six months.

\section{Factors Associated with Condom Use Consistency in the Past Six Months}

In the univariate analysis, four factors were found to be significantly associated with condom use consistency during anal sex in the past six months $(\mathrm{P}<0.05)$. These factors included school type (first-tier college vs vocational college, odds ratio [OR]: 2.129; 95\% CI: 1.101-4.119), student type (undergraduate students vs junior college student, OR: 1.910, 95\% CI: 1.305-3.525), suspicious STD symptoms (yes vs no, OR: 0.384, 95\% CI: 0.183-0.807), and condom use self-efficacy scores $(\geq 15$ vs $<15$, OR: $2.481,95 \%$ CI: 1.422-4.328). These four variables were inserted into the multivariate logistic regression analysis. In the multivariate logistic regression, only three factors were found to be significantly associated with condom use consistency in the past six months: participants from first-tier colleges (OR: 2.522, 95\% CI: 1.255-5.607), high scores in condom use self-efficacy (OR: 2.617, 95\% CI: 1.462-4.685), and suspicious STD symptoms (OR: 0.322, 95\% CI: 0.117-0.889) (Table 3).

\section{Discussion}

This cross-sectional study is one of the few studies that has explored the factors associated with condom use frequency in the past six months among college student MSM in China. Risky sexual behaviors were commonly identified in this study. Higher education institutions and high condom use self-efficacy were associated with consistent condom use in this sample population.

In this study, condom use consistency $(n=119,56 \%)$ when having anal sex with males in the past six months was higher than that in a similar young group in Guangzhou City in a previous meta-analysis in 2015 $(34.8 \%),{ }^{18}$ which had an overall rate of condom use consistency in the past six months of $52.05 \%,{ }^{30}$ and in a recent study in three northern regions in China in 2018 $(41.1 \%) .{ }^{19}$ The rate was also higher than that in international data. In Nigeria, condom use consistency in the past six months in young MSM was $53.0 \%{ }^{31}$ One possible reason for the difference is that the basic HIV control and prevention measures had made progress in China over the years, including issuing basic HIV knowledge for the young, ${ }^{21}$ establishing a school HIV/AIDS epidemic notification system, improving the coverage and pertinence of HIV/AIDS prevention education in schools, and strengthening VCT services and interventions for 
Table 2 Sexual Behaviors Among College Student MSM (N=2|4)

\begin{tabular}{|c|c|}
\hline Character & $\begin{array}{l}\text { Numbers of } \\
\text { Students, } n \text { (\%) }\end{array}$ \\
\hline Age at first sex (years) & \\
\hline$<16$ & $13(6.1 \%)$ \\
\hline $16-18$ & 115 (53.7\%) \\
\hline$>18$ & $86(40.2 \%)$ \\
\hline Gender of first sex partner & \\
\hline Female & $12(5.6 \%)$ \\
\hline Male & $202(94.4 \%)$ \\
\hline Sexual roles with male partners & \\
\hline Only “0” (docile, bottom) & 49 (22.9\%) \\
\hline Only “I” (assertive, top) & $32(15.0 \%)$ \\
\hline Both "0" and "I" & $133(62.1 \%)$ \\
\hline $\begin{array}{l}\text { Numbers of sex partners in the past six } \\
\text { months }\end{array}$ & \\
\hline I & $112(52.3 \%)$ \\
\hline$\geq 2$ & $102(47.7 \%)$ \\
\hline Condom use in the past six months & \\
\hline Never/barely & $18(8.4 \%)$ \\
\hline Barely & $8(3.7 \%)$ \\
\hline Sometimes & $18(8.4 \%)$ \\
\hline Often & $51(23.8 \%)$ \\
\hline Every time & $119(55.6 \%)$ \\
\hline Condom use in their last anal sex & \\
\hline Yes & $163(76.2 \%)$ \\
\hline No & $52(23.8 \%)$ \\
\hline Commercial sex in the past six months & \\
\hline No & $213(99.5 \%)$ \\
\hline Yes & I $(0.5 \%)$ \\
\hline $\begin{array}{l}\text { One-night stand/casual sex in the past six } \\
\text { months }\end{array}$ & \\
\hline No & $119(55.6 \%)$ \\
\hline Yes & $95(44.4 \%)$ \\
\hline $\begin{array}{l}\text { Number of times of one-night stand/casual } \\
\text { sex in the past six months }(\mathrm{N}=95)\end{array}$ & \\
\hline 1 & $40(42.1 \%)$ \\
\hline $2-4$ & $36(37.9 \%)$ \\
\hline$\geq 5$ & $19(20.0 \%)$ \\
\hline $\begin{array}{l}\text { Condom use with one-night stand/casual } \\
\text { partners in the past six months }(N=95)\end{array}$ & \\
\hline Never & $12(12.6 \%)$ \\
\hline Barely & $2(2.1 \%)$ \\
\hline Sometimes & $3(3.2 \%)$ \\
\hline Often & $20(21.0 \%)$ \\
\hline Every time & $58(61.1 \%)$ \\
\hline
\end{tabular}

(Continued)
Table 2 (Continued).

\begin{tabular}{|l|l|}
\hline Character & $\begin{array}{l}\text { Numbers of } \\
\text { Students, n (\%) }\end{array}$ \\
\hline $\begin{array}{l}\text { Regular sex partners in the past six months } \\
\text { No }\end{array}$ & $93(43.5 \%)$ \\
Yes & $121(56.5 \%)$ \\
\hline $\begin{array}{l}\text { Condom use with regular partners in the past } \\
\text { six months }(\mathrm{N}=12 \mathrm{I})\end{array}$ \\
$\begin{array}{l}\text { Never } \\
\text { Barely }\end{array}$ \\
$\begin{array}{l}\text { Sometimes } \\
\text { Often }\end{array}$ & $12(9.9 \%)$ \\
Every time & $11(9.1 \%)$ \\
\hline Female partners in the past six months & $20(16.6 \%)$ \\
No & $70(57.9 \%)$ \\
Yes & $209(97.7 \%)$ \\
\hline Preferable male sex partners & $5(2.3 \%)$ \\
Student MSM & \\
MSM who were employed or had left school & $16(7.5 \%)$ \\
No preference & $90(42.0 \%)$ \\
\hline
\end{tabular}

behaviors. ${ }^{22}$ However, occasional condom use cannot play its full protection role, especially when having sex with an HIV-positive partner. Therefore, developing an HIV prevention program for consistent condom use is important for college student MSM.

Condom use consistency with regular partners was quite low $(\mathrm{n}=70,32.7 \%)$. This finding is supported by previous studies showing that when regular sex partners are involved, young MSM are likely to have condomless anal sex in China ${ }^{32-36}$ and developed countries, such as Sweden $^{37}$ and New Zealand. ${ }^{38}$ Particularly, a study among college student MSM in Beijing reported that believing in unnecessary condom use with a regular sex partner is a significant predictor of $\mathrm{UAI}^{36}$ Similarly, in Hong Kong, the percentage of young MSM who reported consistent condom use during recent anal sex encounters was $39.8 \%$ with regular partners and $54.2 \%$ with non-regular partners. ${ }^{17}$ Sexual roles, trust, chasing romantic symbolic meanings, and "safety negotiation" traps may contribute to a decreased level of cautiousness, leading to unprotected anal sex with regular partners. ${ }^{39}$ 
Table 3 Logistic Regression of Condom Use Frequency in the Past Six Months ( $N=214,0=$ Inconsistent Condom Use; I = Consistent Condom Use)

\begin{tabular}{|c|c|c|c|c|c|}
\hline \multirow[t]{2}{*}{ Variable } & \multirow[t]{2}{*}{ Category } & \multicolumn{2}{|l|}{$\begin{array}{l}\text { Univariate Logistic } \\
\text { Regression }\end{array}$} & \multicolumn{2}{|c|}{$\begin{array}{l}\text { Multivariate Logistic } \\
\text { Regression }\end{array}$} \\
\hline & & OR (95\% Cl) & $\mathbf{P}$ & OR (95\% Cl) & $\mathbf{P}$ \\
\hline \multirow[t]{3}{*}{ School type } & Vocational college & Ref & & & \\
\hline & Second/third-tier universities & NS & & NS & \\
\hline & First-tier universities & $2.129(1.101-4.119)$ & 0.025 & $2.522(1.255-5.067)$ & 0.009 \\
\hline \multirow[t]{2}{*}{ Student type } & Junior college student & Ref & & & \\
\hline & Undergraduate student & $1.910(1.305-3.525)$ & 0.039 & - & \\
\hline \multirow[t]{2}{*}{ Suspected STD symptoms } & No & Ref & & & \\
\hline & Yes & $0.384(0.183-0.807)$ & 0.012 & $0.357(0.163-0.780)$ & 0.01 \\
\hline \multirow[t]{2}{*}{ Scores of self-efficacy of condom use } & $<15$ & Ref & & & \\
\hline & $\geq 15$ & $2.48 \mathrm{I}(\mathrm{I} .422-4.328)$ & 0.001 & $2.617(1.462-4.685)$ & 0.0 .01 \\
\hline
\end{tabular}

Note: - Variables were not included in the multivariate analysis.

Abbreviations: Ref, reference; OR, odds ratio; $\mathrm{Cl}$, confidence interval; NS, not significant in the analysis.

In the current study, the participants with high condom use self-efficacy were likely to report condom use consistency in the past six months, consistent with previous studies. ${ }^{32,40,41}$ Furthermore, in different exceptional circumstances, especially if the sex partner becomes angry at the request for condom use and when the sex partner is intoxicated, the rates of having confidence in consistent condom use markedly decreased at $75.7 \%(\mathrm{n}=162)$ and $81.8 \%(\mathrm{n}=175)$, respectively. This finding shows that the willingness to use condoms might be affected if their partners became unconscious due to alcohol or illicit drug use in this sample. Further studies can explore consistent condom use in these exceptional circumstances, developing improved strategies for safe sex practices and effective ways to negotiate safe sex practice. In addition, condom problems or errors, such as breakage, slippage, late application, and early removal, are common among $\mathrm{MSM}^{42}$ which could reduce the protective value of condoms. Problems that could occur in condom use in this sample were not explored; further studies could fill this gap.

Studying in first-tier colleges is a main factor in consistent condom use. Condom use consistency is associated with good educational background. ${ }^{37,38,43-45}$ As welleducated MSM may have high levels of exposure to HIV/AIDS-related information, ${ }^{45}$ student MSM in first- tier colleges are likely to receive good educational resources and comprehensive HIV-related knowledge.

Surprisingly, multivariate logistic regression results showed that MSM with suspected STD symptoms might perform inconsistent condom use (OR: $0.322,95 \% \mathrm{CI}$ : $0.117-0.889)$ in the past six months. This finding is contrary to a previous study. ${ }^{46}$ There are several possible explanations for this result. First, the question about suspicious STD was

Have you ever had symptoms of a suspected STD (e. g, burning sensation when urinating, abnormal urethral discharge, itching, ulcers, or abnormal growths in the genitals or anus)?

And the question about the consistency of condom use was restricted to the past six months. The MSM who had symptoms of STD may have recovered before this investigation. This means that they did not have suspected STD symptoms during the investigation of the consistency of condom use in the last six months. Second, MSM with suspected STD symptoms might have given up on themselves and decided to enjoy condomless sex to the fullest. Third, this could be a limitation of the cross-sectional study design, which restricted the assessment of the causality of the statistically significant associations with condom use consistency. It is possible that their condomless 
sex with their sex partners contributed to their STD infection.

In this study, although the basic HIV knowledge of most participants $(n=204,95.3 \%)$ was considered "sufficient," college student MSM still engaged in risky sexual behaviors and inconsistent condom use. Thus, knowledge and behavior were inconsistent among college student MSM. These results are consistent with those from a meta-analysis in China. ${ }^{19}$ This phenomenon may be caused by the limitations of sex education in China, both from parents and schools. Sex-related topics are considered sensitive, embarrassing, and highly private in China. ${ }^{47,48}$ Therefore, most parents are not equipped to introduce sex education or HIV prevention education to their children. When students enter college from high school, they face a new living environment and are easily tempted or pushed to perform risky sex practices without self-protection awareness or supervision from parents and teachers. Although safe sex is encouraged, and theories or concepts are most frequently mentioned, strategies for proper condom use, insisting condom use when a sex partner gets upset about using it, and ensuring safety when intoxicated are not discussed in China. If students want additional information on sex topics, they often rely on the internet for answers, where they could be misled by false information that may show that using condoms is not cool or is embarrassing. Therefore, students can be aware of the importance of safe sex but prefer not to use condoms for various reasons. Data from 13 states in the United States showed that HIV-related education could reduce sexual risk behaviors among all students, especially among student MSM. ${ }^{49}$ In the United States, parent-based sex education could increase adolescent engagement in HIV testing and condom use. ${ }^{50}$ However, even in developed countries, such as the United States, sex education led by parents is not common, as one-third of young MSM had never discussed sex topics with their parents. ${ }^{50}$ Tailored sex education by parents could increase the likelihood of HIV testing among student MSM. ${ }^{50}$ Therefore, sex education led by parents is an issue that requires attention from both developed and developing countries. Parents should pay attention to their children's sex education and be actively involved in it, especially parents whose children are MSM. Student MSM are especially vulnerable to stigma and discrimination, which includes possible rejection by schools and families, being gossiped about, being considered to have mental disorders, and loss of employment. ${ }^{47,48,51}$ They need support and guidance from their parents more than their classmates. They may also have extreme ideas when they suffer from stigma or discrimination, such as the irrational and blind attachment to so-called love (e. g, "I know from whom I got infected with HIV, but I love him. .... I'm willing to die with him"), pessimistic view on HIV infection and prevention (e. g, "As the infection is bound to happen sooner or later, perhaps the sooner you get it, the sooner you can get rid of it"), and the wild sense of selfimposed sexual liberation (e. g, "I just want to enjoy my sexual freedom without any restrictions or condoms"). ${ }^{52}$ Sexual communication with parents can be a protective factor in safe sex among young adolescents. ${ }^{53}$ Therefore, parental sex education is imperative, especially before students enter college. In China, children often live with their parents and are supervised by family discipline before they go to college. Once they leave home, they need to make arrangements for themselves and make decisions by themselves, which can be dangerous for those who lack self-protection awareness and family supervision. Further studies can determine how parental sex education affects the sexual behaviors of college student MSM and explore useful strategies for safe sex among them. The introduction of basic HIV information and general sex education by parents or schools and specific strategies for safe sex practices can contribute to healthy sexual behaviors.

Although basic sexual information (e. g, reproductive biology) is always available to the general population in Chinese colleges, it has yet to cater to individual sex education for general students, especially homosexual students. In the United States, student MSM found that sex education materials designed for the general population are not pertinent to their needs. ${ }^{44}$ Data from this study showed that sexual health education for college student MSM was insufficient. Specific evidence-based sex education and safe sex practices should be delivered by acknowledging the appropriate needs of college student MSM and their expectations. ${ }^{9}$ Education on sex information and HIV prevention should focus on safe sex strategies in the context of exceptional circumstances as mentioned above (e. g, under the influence of illicit drugs and alcohol and in a specific issue, such as relationship, power hierarchy, negotiation, etc.). HIV testing, treatment, and prognosis should not be limited to the routes and conditions of transmission. 


\section{Limitations}

This study has several limitations. First, the sample population might not fully represent the overall college student MSM in Changsha City or the general college student MSM population, given that those who were not actively socially connected to the gay community or an app user were not involved. Second, in distributing the questionnaires, the participants' self-reported behaviors could lead to recall and social desirability biases, especially regarding data on risky sex and drug use. The participants who have had an HIV test could be more likely to recall risky behaviors than those who were not tested. Thus, most questions were limited to the past six months of experience to minimize recall bias. Furthermore, the cross-sectional study design has inherent limitations in assessing the causality of the statistically significant associations with condom use consistency. Longitudinal studies are required to investigate the causality between STD and condom use consistency in college student MSM. Further studies with representative samples can provide significant evidence of safe sex strategies for college student MSM.

\section{Conclusion}

Although condom use consistency was relatively high among Chinese college student MSM in this sample, the number of those engaged in risky sexual behaviors was even higher. It is important to develop an HIV prevention program for consistent condom use for college student MSM to help them be more aware of selfprotection and wise in safe sex decision making and to provide them with tailored sex education targeting the specific issues of MSM students. Moreover, HIV knowledge should not be limited to the routes and conditions of transmission. HIV testing, treatment, and prognosis need to be strengthened in the HIV prevention system. Safe sex strategies in the context of exceptional circumstances should also be developed. To help achieve this goal, parents should be engaged in the sex education of their children, particularly before they go to college.

\section{Data Sharing Statement}

The datasets used and/or analyzed in the current study are available from the corresponding author upon reasonable request.

\section{Ethics Approval and Consent to Participate}

This study was conducted in accordance with the Declaration of Helsinki. Ethical approval was obtained from the Institutional Review Board (IRB) of Xiangya Nursing School, Central South University (Changsha, China). Essential information about the study, including its purpose and procedures, the benefits and risks for participants, and their right to decline participation in the study were clearly explained to the participants. As for participants who were between 16 to 18 years old, the parental informed consent was waived by the IRB. There were mainly three reasons for the waiver. First, this study is consistent with the minimal risk ethical standard. Second, people aged 16 and above have the partial capacity for civil conduct. Third, with their intelligence and comprehension, students in this sample can fully understand the purpose, the procedures, the benefits, and the risks of this study. Thus, they can independently decide to participate in this study or not.

\section{Acknowledgments}

The authors gratefully acknowledge the school hospital and the CBO, called Zuo A Cai Hong, for their assistance in the recruitment and for providing places for investigation. The authors thank all the participants for their involvement in this study.

\section{Author Contributions}

All authors made a significant contribution to the work reported, whether that is in the conception, study design, execution, acquisition of data, analysis, and interpretation, or in all these areas; took part in drafting, revising, or critically reviewing the article; gave final approval of the version to be published; have agreed on the journal to which the article has been submitted; and agree to be accountable for all aspects of the work.

\section{Funding}

This study was supported by the Philosophy and Social Science Foundation of Hunan Province (Grant No. 16YBA365). The funding body had no role in the design of the study, in the collection, analysis, and interpretation of data, and in writing the manuscript.

\section{Disclosure}

The authors declare that they have no competing interests. 


\section{References}

1. UNAIDS Data. Global HIV \& AIDS statistics - 2020 fact sheet. Available from: https://www.unaids.org/en/resources/fact-sheet. Accessed April 20, 2021.

2. Chinese Center for Disease Control and Prevention. New progress in the fight against AIDS in China in 2019. Available from: http://www. nhc.gov.cn/jkj/s3586/201911/c2388ce70bdd404ea6dfcd886591784d. shtml. Accessed April 20, 2021.

3. UNAIDS Data 2019. Available from: https://www.unaids.org/en/ resources/documents/2019/2019-UNAIDS-data. Accessed April 20, 2021.

4. Chinese Center for Disease Control and Prevention. About 3000 new cases of AIDS are reported each year among young students aged 15 to 24 years old. Available from: http://www.chinanews.com/gn/2019/ 07-31/8913131.shtml. Accessed April 20, 2021.

5. Wu ZY. Situation and strategy of AIDS prevention and control in Chinese schools. Chin J Sch Health. 2015;36(11):1604-1605.

6 . The health and family planning commission answered questions on dengue fever prevention and control and special action against surrogacy. Available from: http://www.gov.cn/xinwen/2015-04/10/ content_2844813.htm. Accessed April 20, 2021.

7. Tencent News. Young students infected with HIV increased by $35 \%$ annually; $80 \%$ of them were MSM. Available from: http://edu.qq. com/a/20151130/008864.htm. Accessed April 20, 2021.

8. Li W, Chu J, Zhu Z, et al. Epidemiological characteristics of HIV infection among college students in Nanjing, China: a cross-sectional survey. BMJ Open. 2020;10(5):e035889. doi:10.1136/bmjopen-2019035889

9. Xu H, Xie J, Xiao Z, et al. Sexual attitudes, sexual behaviors, and use of HIV prevention services among male undergraduate students in Hunan, China: a cross-sectional survey. BMC Public Health. 2019;19 (1):250. doi:10.1186/s12889-019-6570-2

10. Sun X, Liu X, Shi Y, Wang Y, Wang P, Chang C. Determinants of risky sexual behavior and condom use among college students in China. AIDS Care. 2013;25(6):775-783. doi:10.1080/09540121.2012.748875

11. Cong L, Ono-Kihara M, Xu G, et al. The characterization of sexual behavior in Chinese male university students who have sex with other men: a Cross-Sectional Study. BMC Public Health. 2008;8(1):250. doi:10.1186/1471-2458-8-250

12. Smith DK, Herbst JH, Zhang X, Rose CE. Condom effectiveness for HIV prevention by consistency of use among men who have sex with men in the United States. J Acquir Immune Defic Syndr. 2015;68 (3):337-344. doi:10.1097/QAI.0000000000000461

13. Mao YX, Xiao CC, Wang T, Li SY, Yan H. One-night-stand behavior and associated factors among young men who have sex with men in Wuhan, China. Zhonghua Liu Xing Bing Xue Za Zhi. 2017;38 (6):746-749. doi:10.3760/cma.j.issn.0254-6450.2017.06.011

14. Garofalo R, Hotton AL, Kuhns LM, Gratzer B, Mustanski B. Incidence of HIV infection and sexually transmitted infections and related risk factors among very young men who have sex with men. J Acquir Immune Defic Syndr. 2016;72(1):79-86. doi:10.1097/ QAI.0000000000000933

15. Balan IC, Frasca T, Pando MA, et al. High substance use and HIV risk behavior among young Argentine men who have sex with men. AIDS Behav. 2018;22(4):1373-1382. doi:10.1007/s10461-017-1987-z

16. Yeo TE, Ng YL. Sexual risk behaviors among apps-using young men who have sex with men in Hong Kong. AIDS Care. 2016;28 (3):314-318. doi:10.1080/09540121.2015.1093597

17. Hoenigl M, Chaillon A, Morris SR, Little SJ. HIV infection rates and risk behavior among young men undergoing community-based testing in San Diego. Sci Rep. 2016;6(1):25927. doi:10.1038/srep25927

18. Yang Z, Huang Z, Dong Z, Zhang S, Han J, Jin M. Prevalence of high-risk behaviors in the transmission of HIV among high school and college student MSM in China: a meta-analysis. BMC Public Health. 2015;15(1):1272. doi:10.1186/s12889-015-2614-4
19. Zhang DC, Wu ZY, Scott SR. Factors associated with unprotected anal intercourse among male students who have sex with men in three northern regions of China. Chin Med J. 2019;132 (14):1639-1644. doi:10.1097/CM9.0000000000000311

20. Ministry of Education of the People's Republic of China. Notice on strengthening health education on AIDS prevention in schools. Available from: http://www.moe.gov.cn/s78/A17/twys_left/moe_943/ moe_945/s3285/201006/t20100603_88666.html. Accessed April 20, 2021.

21. Ministry of Education of the People's Republic of China. Basic knowledge on HIV/AIDS prevention for youth. Available from: http://old.moe.gov.cn//publicfiles/business/htmlfiles/moe/s3285/ 201001/xxgk_81038.html. Accessed April 20, 2021.

22. Ministry of Education of the People's Republic of China. University HIV reporting mechanism will be established in China in 2015. Available from: http://www.moe.gov.cn/jyb_xxgk/moe_1777/moe 1779/201510/t20151019_214246.html. Accessed May 7, 2021.

23. Ministry of Education of the People's Republic of China. Notice on further strengthening HIV/AIDS prevention education in schools in the new era. Available from: http://www.moe.gov.cn/jyb_xwfb/gzdt_gzdt/ s5987/201910/t20191014_403367.html. Accessed April 14, 2021.

24. Guo WG, Mao NL, Shen ZY. Challenges and strategies for HIV/ AIDS prevention and control in schools. Pract Prev Med. 2020;27 (11):1403-1405.

25. Rotheram-Borus MJ, Koopman C. Sexual risk behavior, AIDS knowledge, and beliefs about AIDS among predominantly minority gay and bisexual male adolescents. AIDS Educ Prev. 1991;3 (4):305-312.

26. The AIDS Prevention Working Committee Office of the State Council. China AIDS monitoring and assessment framework (trial). In: Li Y, Guochen H, editors. 2008 China Health Statistics Yearbook. Beijing: People's Medical Publishing House; 2008:232.

27. Thorpe L, Ford K, Fajans P, Wirawan DN. Correlates of condom use among female prostitutes and tourist clients in Bali, Indonesia. AIDS Care. 1997;9(2):181-197. doi:10.1080/09540129750125208

28. Yu F. The Efficacy of Intervention on Risk Behavior via Peer-Group Among MSM. Hefei City (D): Anhui Medical School; 2011.

29. IBM SPSS statistics 25.0. Available from: https://www.ibm.com/sup port/pages/node/589145. Accessed April 20, 2021.

30. Jiang H, Chen X, Li J, Tan Z, Cheng W, Yang Y. Predictors of condom use behavior among men who have sex with men in China using a modified information-motivation-behavioral skills (IMB) model. BMC Public Health. 2019;19(1):261. doi:10.1186/s12889019-6593-8

31. Stromdahl S, Onigbanjo Williams A, Eziefule B, et al. Associations of consistent condom use among men who have sex with men in Abuja, Nigeria. AIDS Res Hum Retroviruses. 2012;28 (12):1756-1762. doi:10.1089/aid.2012.0070

32. Wang C, Tucker JD, Liu C, Zheng H, Tang W, Ling L. Condom use social norms and self-efficacy with different kinds of male partners among Chinese men who have sex with men: results from an online survey. BMC Public Health. 2018;18(1):1175. doi:10.1186/s12889018-6090-5

33. Wang Y, Jia M, Yuan D, et al. Assessing consistent condom use among migrant men who have sex with men in Shanghai, China: validation of an information-motivation-behavioral skills model. BMC Infect Dis. 2019;19(1):462. doi:10.1186/s12879-019-4090-4

34. Chow EP, Wilson DP, Zhang L. Patterns of condom use among men who have sex with men in China: a systematic review and meta-analysis. AIDS Behav. 2012;16(3):653-663. doi:10.1007/ s10461-011-9935-9

35. Lau JT, Cai W, Tsui HY, et al. Prevalence and correlates of unprotected anal intercourse among Hong Kong men who have sex with men traveling to Shenzhen, China. AIDS Behav. 2013;17 (4):1395-1405. doi:10.1007/s10461-012-0244-8 
36. Zheng J, Wu Z, Poundstone KE, Pang L, Rou K. HIV, syphilis infection, and risky sexual behaviors among male university students who have sex with men in Beijing, China: a Cross-Sectional Study. AIDS Educ Prev. 2012;24(1):78-88. doi:10.1521/ aeap.2012.24.1.78

37. Johansson K, Persson KI, Deogan C, El-Khatib Z. Factors associated with condom use and HIV testing among young men who have sex with men: a cross-sectional survey in a random online sample in Sweden. Sex Transm Infect. 2018;94(6):427-433. doi:10.1136/sextrans-2017-053369

38. Lachowsky NJ, Saxton PJW, Hughes AJ, et al. Frequent condom use with casual partners varies by sexual position among younger gay and bisexual men in New Zealand: national behavioral surveillance 2006-2011. Sex Health. 2016;13(1):81-86. doi:10.1071/SH14220

39. Yeo TE, Fung TH. Between " 0 " and " 1 ": safer sex and condom use among young gay men in Hong Kong. Cult Health Sex. 2016;18 (3):294-307. doi:10.1080/13691058.2015.1080298

40. Safren SA, Blashill AJ, Lee JS, et al. Condom-use self-efficacy as a mediator between syndemics and condomless sex in men who have sex with men (MSM). Health Psychol. 2018;37(9):820-827. doi:10.1037/hea0000617

41. Ma Q, Ono-Kihara M, Cong L, et al. Behavioral and psychosocial predictors of condom use among university students in Eastern China. AIDS Care. 2009;21(2):249-259. doi:10.1080/09540120801982921

42. Crosby R, Mena L, Yarber WL, Graham CA, Sanders SA, Milhausen RR. Condom use errors and problems: a comparative study of HIV-positive versus HIV-negative young Black men who have sex with men. Sex Transm Dis. 2015;42(11):634-636. doi:10.1097/OLQ.0000000000000356

43. Jin M, Yang Z, Dong Z, Han J. Correlates of consistent condom use among men who have sex with men recruited through the internet in Huzhou City: a cross-sectional survey. BMC Public Health. 2013;13 (1):1101. doi:10.1186/1471-2458-13-1101

44. Balaji AB, Bowles KE, Le BC, Paz-Bailey G, Oster AM. High HIV incidence and prevalence and associated factors among young MSM, 2008. AIDS. 2013;27(2):269-278. doi:10.1097/QAD.0b013e32835ad489

45. Mandiwa C, Namondwe B. Uptake and correlates of HIV testing among men in Malawi: evidence from a national population-based household survey. BMC Health Serv Res. 2019;19(1):203. doi:10.1186/s12913-019-4031-3
46. Abara WE, Oraka E, Jeffries Iv WL, Chavez P, Nasrullah M, DiNenno E. Prevalence and correlates of condom use among sexually active men who have sex with men in the United States: findings from the national survey of family growth, 2002, 2006-10 and 2011-13. Sex Health. 2017;14(4):363-371. doi:10.1071/SH16034

47. Wei C, Cheung DH, Yan H, Li J, Shi LE, Raymond HF. The impact of homophobia and HIV stigma on HIV testing uptake among Chinese men who have sex with men: a mediation analysis. J Acquir Immune Defic Syndr. 2016;71(1):87-93. doi:10.1097/ QAI.0000000000000815

48. Wu F, Zhang A, Babbitt A, et al. Overcoming HIV stigma? A qualitative analysis of HIV cure research and stigma among men who have sex with men living with HIV. Arch Sex Behav. 2018;47 (7):2061-2069. doi:10.1007/s10508-017-1062-x

49. Raifman J, Beyrer C, Arrington-Sanders R. HIV education and sexual risk behaviors among young men who have sex with men. $L G B T$ Health. 2018;5(2):131-138. doi:10.1089/lgbt.2017.0076

50. Pierce JD, Ylitalo KR, Lanning BA, Limbers CC. Sex education and HIV testing among young men who have sex with men: findings from the 2006-2010 and 2011-2015 national survey of family growth. J Acquir Immune Defic Syndr. 2018;79(2):179-185. doi:10.1097/QAI.0000000000001773

51. Feng Y, Wu Z, Detels R. Evolution of men who have sex with men community and experienced stigma among men who have sex with men in Chengdu, China. J Acquir Immune Defic Syndr. 2010;53 (Supp11):S98-103. doi:10.1097/QAI.0b013e3181c7df71

52. Yi JF. Challenges and responses to HIV/AIDS prevention and control in colleges. Chin J Sch Doctor. 2017;31(06):405-406+409.

53. Widman L, Choukas-Bradley S, Noar SM, Nesi J, Garrett K. Parentadolescent sexual communication and adolescent safer sex behavior: a meta-analysis. JAMA Pediatr. 2016;170(1):52-61. doi:10.1001/ jamapediatrics.2015.2731
HIV/AIDS - Research and Palliative Care

\section{Publish your work in this journal}

HIV/AIDS - Research and Palliative Care is an international, peerreviewed open-access journal focusing on advances in research in HIV, its clinical progression and management options including antiviral treatment, palliative care and public healthcare policies to
Dovepress

control viral spread. The manuscript management system is completely online and includes a very quick and fair peer-review system, which is all easy to use. Visit http://www.dovepress.com/testimonials.php to read real quotes from published authors. 